Original Article

\title{
Incidence of Depression and Anxiety in Patients with Acute Myocardial Infarction (AMI) during COVID-19 Pandemic
}

\author{
Saima Dastgeer ${ }^{1}$, Abubakr Ali Saad ${ }^{2}$, Shabbih Fatima ${ }^{3}$, Imran Javaid ${ }^{2}$, Khalil-ur-Rehman ${ }^{2}$ \\ Rizwana Amin ${ }^{4}$ \\ ${ }^{1}$ Department of Psychology, Government College of Home Economics, Multan, Pakistan. \\ ${ }^{2}$ Department of Cardiology, D. G. Khan Medical College \& Teaching Hospital, Dera Ghazi Khan, Pakistan \\ ${ }^{3}$ Department of Applied Psychology, The Islamia University of Bahawalpur, Pakistan. \\ ${ }^{4}$ Department of Professional Psychology, Bahria University Islamabad Campus, Islamabad - Pakistan
}

\begin{abstract}
Objective: This study aimed to assess the incidence of anxiety and depression among AMI patients during COVID-19 pandemic in Pakistan.

Material \& Method: This cross-sectional study was conducted from February 27 to June 2, 2020, at the Cardiology ward of Dera Ghazi Khan Teaching Hospital. Total 611 patients selected through convenience sampling. The patients were requested to respond to Hospital Anxiety and Depression Scale (HADS) and demographic information. An independent samples t test was applied for comparisons.
\end{abstract}

Results: Patients' age was ranging from 41 to 79 years, with a mean age of $52.35 \pm 5.12$. There was a high frequency of anxiety (51.72\%) and depression (34.86\%) among AMI patients. A significant difference was observed in the level of anxiety $(p=0.001)$ and depression $(p=0.000)$ among male and female patients.

Conclusion: The present study findings affirmed that increased level of anxiety and depression are prevalent in AMI patients. Additionally, both anxiety and depressive symptoms were more common in female patients.

Keywords: COVID-19, Anxiety, Depression, Acute Myocardial Infarction (AMI).

Corresponding Author: Abubakr Ali Saad

Department of Cardiology, D. G. Khan Medical College \& Teaching Hospital, Dera Ghazi Khan, Pakistan

Email: cardiologistmic@gmail.com

Date of Submission: $26-10-2020$

Date of Revision: 08-12-2020

Date of Online Publishing: 25-12-2020

Date of Print: $30-12-2020$

DOI: $10.36552 /$ pjns.v24i4.473

\section{INTRODUCTION}

COVID-19 is declared as a global health crisis with high death rates and infected individuals. Cardiac patients are particularly at high risk of dying from COVID-19 due to their ill health and vulnerability for a myocardial involvement. ${ }^{1}$ Acute myocardial infarction (AMI) is a cardiac emergency and needs immediate diagnosis and treatment. Therefore, 
COVID-19 the highly infectious pneumonia affects the diagnosis and treatment of AMI. According to World health organization, ${ }^{2}$ depression is the second leading reason of disability worldwide by 2020. Depression is an important root cause of mental illness and death, especially in patients with heart disease. Depression and anxiety are thought of as one of the main reasons of morbidity and death in patients with heart disease, such as myocardial infarction (MI). ${ }^{3,4,5}$ Thus, MI is a serious, life-threatening event which can increase the risk for depression and anxiety. ${ }^{6,7}$

After the occurrence of any acute cardiac event such as AMI, both anxiety and depression are common to happen. In general, it is acceptable for one in five patients diagnosed with depression and one in three to suffer from severe anxiety symptoms during hospitalization for heart disease. ${ }^{8,9,10}$ Patients who suffer from anxiety or depression after experiencing an acute cardiac event are at greater risk of going through later events and even untimely death. ${ }^{11}$ Adverse health effects appear or are exacerbated when signs of anxiety or depression persist or occur after discharge from the hospital or during recovery from cardiac event. $12,13,14$ It has been found through a 12 - years follow-up study that 170 women with $\mathrm{AMI}$ and coronary artery bypass graft surgery $(C A B G)$ have the highest mortality rate whose depressive symptoms are worsened and lowest among those women whose symptoms have improved in the two months after discharge from the hospital. ${ }^{12}$ Even anxiety symptoms remaining for one to two months after post-event increases the risk for an adverse cardiac event. ${ }^{15}$ Therefore, screening patients who are at risk of developing signs and symptoms of anxiety or depression is very important, not only those whose symptoms are present during hospitalization but also develop after recovering from any cardiac event. ${ }^{10}$

In recent years, the mechanisms of the association between coronary heart disease (CHD) and mental health are well recorded in various published reviews. It is proposed that CHD, anxiety, and depression have many common biological mechanisms. For example, individual having depressive symptoms can also have a high level of biological makers that increase atherosclerosis. Both anxiety and depression decreased parasympathetic activities are suggestive of decrease in the variability heart rate, alteration in serotonergic pathways as well as in platelet aggregability, and increased level of C-reactive protein, which is a sign of high inflammatory response. Another mechanism involves impairment of the cardiac neuronal reuptake of noradrenaline in the heart in patients with anxiety and depressive symptoms. ${ }^{16}$

Thus, the present study is carried out to assess the incidence of anxiety and depression among Acute Myocardial Infarction patients during the COVID-19 pandemic. Although studies have been conducted in Pakistan to assess anxiety and depression in Acute Myocardial Infarction patients, but this research study contributes to the existing literature through studying anxiety and depression in times ofCOVID-19.

\section{MATERIAL \& METHODS}

\section{Study Setting and Design}

A cross-sectional study was completed with 611 Acute Myocardial Infarction patients (male $=367$, female $=244$ ) after obtaining consent from them. The patients were included from the Cardiology Ward of Dera Ghazi Khan Teaching Hospital from February 27 to June 2, 2020. The convenience sampling technique was used.

\section{Data Collection}

Only those patients were included, who were survived from Acute Myocardial Infarction (AMI). Non-survivors were excluded from the study. The approached patients were then requested to fill out the questionnaires. They were also asked to 
provide demographic information about their gender, age, education, marital status, family system, and occupation.

\section{Instrument}

The Hospital Anxiety and Depression Scale (HADS), ${ }^{17}$ is one of the widely applied instruments to assess anxiety and depressive symptoms. The present study used HADS Urdu translated version developed by Mumford et al, for the convenience of patients. HADS comprised of 14 items, seven items for each subscale. The participants gave their responses about their experience over the past week. The maximum score was, therefore, 21 for depression and anxiety. As HADS was a very brief instrument, so it took only 5 to 10 minutes to complete it. HADS scores for each subscale were categorized into three; these are: (i) Normal ranged from 1 to 7, (ii) borderline ranged from 8 to 10, and (iii) abnormal ranged from 11 to 21 . Cronbach's alpha for HADS-A varied from .68 to .93 and for HADS-D from .67 to .90 .

\section{Statistical Calculation}

All the participants were selected through convenience sampling and asked to provide their responses on a booklet containing study instrument and demographic information sheet. They were ensured about the confidentiality of their responses to the questionnaires. Descriptive statistics and independent sample t- test were computed in SPSS-23 to analyze the data.

\section{RESULTS}

\section{Background Information}

Patients' age was ranging from 41 to 79 years, with a mean age of $52.35 \pm 5.12$. Table 1 shows a sample of 611 (male $=60.07 \%$, female $=39.93 \%$ ) patients with Acute Myocardial Infarction. Patients' age range was categorized into four groups, i.e. 40 to 49 (4.73\%), 50 to 59 (28.31\%), 60 to 69 (34.21\%) and 70 to 79 (22.75\%). Educational level was also categorized into four types; these were matriculation, intermediate, bachelors, and masters; therefore, most of the patients had completed their matriculation i.e., 52.86\%. Hence, $85.76 \%$ of the patients reported that they were married and living in a joint family system (77.09\%) and doing some kind of job (71.19\%). Scores on the HADS anxiety scale showed that most patients lie in the abnormal range (51.72\%) whereas, HADS depression scale score depicted that most patients were of borderline (58.27\%).

Table 1: Descriptive Characteristics of the Patients with Acute Myocardial Infarction (AMI).

\begin{tabular}{lrc|} 
Characteristics of Patients & N & Percentage (\%) \\
Gender & & \\
Male & 367 & 60.07 \\
Female & 244 & 39.93 \\
Age & & \\
40-49 years & 90 & 14.73 \\
50-59 years & 173 & 28.31 \\
$60-69$ years & 209 & 34.21 \\
70-79 years & 139 & 22.75 \\
Educational Level & & \\
Matriculation & 323 & 52.86 \\
Intermediate & 115 & 18.82 \\
Bachelors & 92 & 15.06 \\
Masters & 81 & 13.26 \\
Marital Status & & \\
Single & 74 & 12.11 \\
Married & 524 & 85.76 \\
Divorced & 13 & 2.13 \\
Family System & & \\
Joint & 471 & 77.09 \\
Nuclear & 140 & 22.91 \\
Occupation & & \\
Yes & 435 & 71.19 \\
No & 118 & 19.31 \\
House wife & 85 & 9.49 \\
Anxiety Level & & \\
Normal & 8 & 1.31 \\
Borderline & 287 & 46.97 \\
Abnormal & 316 & 51.72 \\
Depression Level & & \\
Normal & 42 & 6.87 \\
Borderline & 356 & 58.27 \\
Abnormal & 213 & 34.86 \\
\hline
\end{tabular}




\section{Comparison between Male and} Female Patients on the Levels of Anxiety and Depression

Table 2 shows a significant difference in the level of anxiety ( $\mathrm{t}(609)=4.535, \mathrm{p}<$ 0.05 ) and depression ( $\mathrm{t}(609)=6.905, \mathrm{p}$ $<0.05$ ) among male and female patients with Acute Myocardial Infarction. Thus, this result helped us to conclude that anxiety and depression were more prevalent in female patients with AMI.

\section{DISCUSSION}

The current study findings presented an initial view of the incidence of anxiety and depression among Acute Myocardial Infarction patients during the COVID-19 pandemic in Pakistan. Depression and anxiety are known as one of the major risk factors for unfavorable medical conditions in patients with AMI.

The result of the present study reveals that anxiety (51.72\%) and depression (34.86\%) have a high frequency rate among AMI patients. During COVID-19 pandemic significant increase in anxiety $^{19}$ and depression have been found; however, similar findings in the context of depression have been reported by Maqsood et al. ${ }^{20}$ In another study, cardiac problems are highly related to anxiety and depressive symptoms. $^{21}$

In the current study, significant differences have been obtained in the level of anxiety and depression among male and female patients and, also elevated levels of anxiety and depression are found in females as compared to male patients. These results are supported by previous researches that female patients experience high levels of anxiety and depressive symptoms when compared to male patients. ${ }^{22}$ Whereas, in cardiac patients, anxiety and depressive symptoms are generally more common concerns for male and female. On the other hand, female heart patients often have more symptoms of depression and anxiety than male patients. ${ }^{23}$

Although significant findings are revealed in the current study, but this should be considered in the light of some limitations. However, a sample is not enough to generalize the findings; thus, data should be collected from a large number of patients to generalize it. The sample is only limited to the Cardiology ward of Dera Ghazi Khan Teaching Hospital; thus, future researches should consider collecting samples from other hospitals too. Additionally, long term follow-up for anxiety and depressive signs and symptoms in patients are not taken due to limited time, therefore, future studies should also work on it.

\section{CONCLUSION}

The present study findings affirmed that a high level of anxiety and depression are prevalent in AMI during COVID-19 pandemic. Additionally, both anxiety and depression symptoms were more common in female patients. Thus, in the AMI treatment plan, psychiatric/psychologist consultation should be included in the management of anxiety and depressive symptoms.

\section{REFERENCES}

1. Inciardi RM, Lupi L, Zaccone G, Italia L, Raffo M, Tomasoni D, Cani DS, Cerini M, Farina D, Gavazzi E, Maroldi R. Cardiac involvement in a patient with 
coronavirus disease 2019 (COVID-19). JAMA cardiology, 2020 March 27.

2. World Health Organization. Mental health: a call for action by world health ministers. In Mental health: a call for action by World Health Ministers 2001: pp. 163-163.

3. Chaddha A, Robinson EA, Kline-Rogers $E$, Alexandris-Souphis T, Rubenfire M. Mental health and cardiovascular disease. The American journal of medicine, 2016 Nov. 1; 129 (11): 1145-8.

4. Kozela M, Bobak M, Besala A, Micek A, Kubinova R, Malyutina S, Denisova D, Richards $M$, Pikhart $H$, Peasey A, Marmot $M$. The association of depressive symptoms with cardiovascular and allcause mortality in Central and Eastern Europe: prospective results of the HAPIEE study. European journal of preventive cardiology, 2016; 23 (17): 1839-47.

5. Roest AM, Zuidersma M, de Jonge P. Myocardial infarction and generalised anxiety disorder: 10year follow-up. The British Journal of Psychiatry, 2012; 200 (4): 324-9.

6. Krumholz HM. Where have all the heart attacks gone? New York Times. April 6, 2020.

7. Garcia S, Albaghdadi MS, Meraj PM, et al. Reduction in ST segment elevation cardiac catheterization laboratory activations in the United States during COVID-19 pandemic. J Am Coll Cardiol. 2020 (Epub ahead of print).

8. Tully PJ, Baker RA. Depression, anxiety, and cardiac morbidity outcomes after coronary artery bypass surgery: a contemporary and practical review. Journal of geriatric cardiology: JGC. 2012; 9 (2): 197.

9. Colquhoun DM, Bunker SJ, Clarke DM, Glozier N, Hare DL, Hickie IB, Tatoulis J, Thompson DR, Tofler $\mathrm{GH}$, Wilson A, Branagan MG. Screening, referral and treatment for depression in patients with coronary heart disease. Medical Journal of Australia, 2013; 198 (9): 483-4.

10. Murphy BM, Higgins RO, Jackson AC. Anxiety, depression, and psychological adjustment after an acute cardiac event. Handbook of Psychocardiology, 2016.

11. Tully PJ, Cosh SM, Baune BT. A review of the affects of worry and generalized anxiety disorder upon cardiovascular health and coronary heart disease. Psychology, health \& medicine, 2013; 18 (6): 627-44.

12. Murphy $B$, Rogerson $M$, Worcester $M$, Elliott $P$, Higgins $R$, Le Grande $M$, Turner A, Goble A. Predicting mortality 12 years after an acute cardiac event: comparison between in hospital and 2month assessment of depressive symptoms in women. Journal of cardiopulmonary rehabilitation and prevention, 2013; 33 (3): 160-7.

13. Worcester MU, Goble AJ, Elliott PC, Froelicher ES, Murphy BM, Beauchamp AJ, Jelinek MV, Hare DL. Mild depression predicts long-term mortality after acute myocardial infarction: a 25-year follow-up. Heart, Lung and Circulation, 2019; 28 (12): 1812-8.

14. Kim JM, Stewart R, Kim JW, Kang HJ, Kim SW, Shin IS, Hong YJ, Ahn Y, Jeong MH, Yoon JS. Impact of depression at early and late phases following acute coronary syndrome on long-term cardiac outcomes. Journal of affective disorders, 2020; 260: 592-6.

15. Frasure-Smith $N$, Lespérance $F$. Depression and anxiety as predictors of 2-year cardiac events in patients with stable coronary artery disease. Archives of general psychiatry, 2008; 65 (1): 62-71.

16. Alvarenga $M E$, Richards JC, Lambert G, Esler MD. Psychophysiological mechanisms in panic disorder: a correlative analysis of noradrenaline spillover, neuronal noradrenaline reuptake, power spectral analysis of heart rate variability, and psychological variables. Psychosomatic Medicine, 2006; 68 (1): 816.

17. Zigmond AS, Snaith RP. The hospital anxiety and depression scale. Acta psychiatrica scandinavica. 1983; 67 (6): 361-70.

18. Mumford DB, Tareen IA, Bajwa MA, Bhatti MR, Karim R. The translation and evaluation of an Urdu version of the Hospital Anxiety and Depression Scale. Acta Psychiatrica Scandinavica. 1991; 83 (2): 81-5.

19. Cullen W, Gulati G, Kelly BD. Mental health in the COVID-19 pandemic. QJM: An International Journal of Medicine, 2020; 113 (5): 311-2.

20. Maqsood S, Khan MN, Hayat U, Ajmal S, Mushtaq M, Khan MN, Shah SF, Khan HN. Depression in myocardial infarction patients at Ayub teaching hospital Abbottabad. Journal of Ayub Medical College Abbottabad, 2017; 29 (4): 641-4. 
21. Phillips AC, Batty GD, Gale CR, Deary IJ, Osborn D, Maclntyre K, et al. Generalized anxiety disorder, major depressive disorder, and their comorbidity as predictors of all-cause and cardiovascular mortality: the Vietnam experience study. Psychosom Med. 2009; 71: 395-403.

22. Serpytis P, Navickas P, Lukaviciute L, Navickas A, Aranauskas R, Serpytis R, Deksnyte A, Glaveckaite $\mathrm{S}$, Petrulioniene Z, Samalavicius R. Gender-based differences in anxiety and depression following acute myocardial infarction. Arquivos brasileiros de cardiologia. 2018; 111 (5): 676-83.

23. Anderson L, Oldridge N, Thompson DR, Zwisler $A D$, Rees K, Martin N, Taylor RS. Exercise-based cardiac rehabilitation for coronary heart disease: Cochrane systematic review and meta-analysis. Journal of the American College of Cardiology, 2016; 67 (1): 1-2.

\section{Additional Information}

Disclosures: Authors report no conflict of interest.

Ethical Review Board Approval: The study was conformed to the ethical review board requirements.

Human Subjects: Consent was obtained by all patients/participants in this study.

\section{Conflicts of Interest:}

In compliance with the ICMJE uniform disclosure form, all authors declare the following:

Financial Relationships: All authors have declared that they have no financial relationships at present or within the previous three years with any organizations that might have an interest in the submitted work.

Other Relationships: All authors have declared that there are no other relationships or activities that could appear to have influenced the submitted work.

\section{AUTHORS CONTRIBUTIONS}

\begin{tabular}{|l|l|l|l|}
\hline Sr.\# & Author's Full Name & Intellectual Contribution to Paper in Terms of: \\
\hline 1. & Saima Dastgeer & 1. $\quad$ Study design and methodology. \\
\hline 2. & Abubakr Ali Saad & 2. $\quad$ Paper writing, referencing, and data calculations. \\
\hline 3. & Shabbih Fatima & 3. $\quad$ Data collection and calculations. \\
\hline 4. & Imran Javaid & 4. Analysis of data and interpretation of results. \\
\hline 5. & Khalil-ur-Rehman. & 5. $\quad$ Literature review and manuscript writing. \\
\hline 6. & Rizwana Amin & 6. $\quad$ Analysis of data and quality insurer. \\
\hline
\end{tabular}

